\title{
Changes in body fat distribution through menopause increase blood pressure independently of total body fat in middle-aged women: the Korean National Health and Nutrition Examination Survey 2007-2010
}

\author{
Jin Kyu Park ${ }^{1}$, Young-Hyo Lim ${ }^{1}$, Kyung-Soo Kim ${ }^{1}$, Soon Gil Kim² ${ }^{2}$, Jeong Hyun Kim ${ }^{1}$, Heon Gil Lim ${ }^{1}$ \\ and Jinho Shin ${ }^{1}$
}

Blood pressure in women increases sharply in middle age, especially after menopause. As the menopausal transition is known to induce changes in body fat distribution, the aim of this study was to investigate the effect of body fat distribution as compared with the effect of total body fat on blood pressure through the menopausal transition. We analyzed 1422 subjects aged 45-55 years using the database from the Korean National Health and Nutrition Examination Survey 2007-2010. The waist circumference (WC) of post-menopausal women was larger than that of pre-menopausal women $(80.44 \mathrm{~cm}, 95 \%$ confidence interval (CI) $79.36-81.52$ vs. $78.94 \mathrm{~cm}, 95 \% \mathrm{Cl} 78.27-79.61, P=0.013$ ), but there was no statistically significant difference in body mass index (BMI). Systolic and diastolic blood pressure (SBP and DBP) were significantly higher in post-menopausal women than in pre-menopausal women: $\mathrm{SBP}$ was $118.33 \mathrm{~mm} \mathrm{Hg}, 95 \% \mathrm{Cl} 116.52-120.15$ vs. $115.22 \mathrm{~mm} \mathrm{Hg}, 95 \% \mathrm{Cl} 114.17-116.28(P=0.003)$ and DBP was $76.94 \mathrm{~mm} \mathrm{Hg}, 95 \% \mathrm{Cl} 75.88-77.99$ vs. $75.25 \mathrm{~mm} \mathrm{Hg}$, $95 \% \mathrm{Cl} 74.57-75.93(P=0.009)$. BMI and WC were positively correlated with BP. After adjustment for $\mathrm{BMI}$, the correlation of WC with SBP remained significant $(\beta=0.250,95 \% \mathrm{Cl} 0.024-0.476, P=0.030)$. In a stratified analysis, WC correlated with SBP in women with $\mathrm{BMI}<25 \mathrm{~kg} \mathrm{~m}^{-2}(\beta=0.358,95 \% \mathrm{Cl} 0.138-0.579, P=0.001)$, but not in women with BMI $\geqslant 25 \mathrm{~kg} \mathrm{~m}^{-2}$. We conclude that the changes in body fat distribution through the menopausal transition are associated with SBP, independent of total body fat. This finding indicates that alterations in the localization of body fat are another cause of menopause-related changes in BP.

Hypertension Research (2013) 36, 444-449; doi:10.1038/hr.2012.194; published online 13 December 2012

Keywords: blood pressure; body fat distribution; central obesity; menopause; waist circumference

\section{INTRODUCTION}

The age-related increase in blood pressure accelerates through the menopausal transition, ${ }^{1-3}$ and the prevalence of hypertension appears to be higher in menopausal women that in age-matched men. ${ }^{1,4,5}$ The hormonal changes that occur after menopause have been thought to be contributing factors. ${ }^{6,7}$ However, hypotheses implicating other physiological changes have been suggested as a result of clinical and animal studies; 8,9 these include aging, ${ }^{10-12}$ obesity ${ }^{13}$ and physical activity. ${ }^{14}$ Among these, total body fat, weight and body mass index (BMI) have been shown to be strongly correlated with blood pressure. ${ }^{15-18}$ Central obesity also has an effect on blood pressure, ${ }^{19,20}$ and changes in body composition and fat distribution are known to occur after menopause. ${ }^{21-25}$ Therefore, it is reasonable to suppose that the menopause-related changes in blood pressure are partly due to changes in fat distribution in middle-aged women.
According to several reviews, ${ }^{26-29}$ the relationships between age, menopause, body fat distribution and blood pressure are rather unclear and have not been evaluated in population-based studies. In this study, we investigated the association between the menopauserelated effects on body fat distribution and blood pressure in middleaged women in the population using data from the Korean National Health and Nutrition Examination Survey (KNHANES) 2007-2010.

\section{METHODS \\ 2007-2010 KNHANES}

This study was based on data obtained from the KNHANES 2007 to 2010, representing the KNHANES IV (2007-2009) and the first year of the KNHANES V (2010), which used a rolling sampling design that involved a complex, stratified, multistage, probability-clustered survey of a representative sample of the non-institutionalized civilian population of South Korea. The

${ }^{1}$ Division of Cardiology, Department of Internal Medicine, College of Medicine, Hanyang University Medical Center, Seoul, Korea and ${ }^{2}$ Division of Cardiology, Department of Internal Medicine, College of Medicine, Hanyang University Guri Hospital, Guri, Korea

Correspondence: Dr J Shin, Division of Cardiology, Department of Internal Medicine, Hanyang University Medical Center, Sungdong-gu, Wangsipriro 222, Seoul 133-070, Korea. E-mail: jhs2003@hanyang.ac.kr

Received 29 June 2012; revised 17 September 2012; accepted 16 October 2012; published online 13 December 2012 
survey consisted of three components, the Health Interview Survey on general health conditions and health-related lifestyle, the Nutrition Survey for dietary assessment and the Health Examination Study on prevalent chronic diseases. The field survey in the KNHANES was conducted throughout the year by specially trained interviewers at mobile centers and in the participants' households. The health interviews and health examination surveys were performed in specially designed and equipped mobile centers, which traveled to locations throughout the country. The interviewer was not given any information about specific participants before performing the interviews and all of the participants provided written consent to participate in the study. Details of the surveys can be found by consulting items in the reference section. ${ }^{30,31}$

\section{Analyzed participants}

In the 2007-2010 KHNANES database, the mean age of natural menopause was 49.08 years (95\% confidence intervals (CIs) 48.93-49.23). Therefore, we analyzed 2554 middle-aged women ranging from 45 to 55 years of age whose history of menopause and blood pressure were available. We excluded postmenopausal women who had undergone surgical menopause or hysterectomy (280 women) and women who were taking an oral contraceptive or hormone replacement agent (594 women). We also excluded 258 women who had recently (past year or less) developed menopause. This left us with 1422 women (1029 pre-menopausal and 393 post-menopausal women) suitable for this study.

\section{Anthropometry}

Height, body weight and waist circumference (WC) measurements were conducted by trained examiners. Height was measured to the nearest $1 \mathrm{~mm}$ with a portable stadiometer (Seriter, Bismarck, ND, USA) with the subject standing barefoot. Body weight was measured to the nearest $0.1 \mathrm{~kg}$ with a calibrated balanced-beam scale (Giant-150N; Hana, Seoul, Korea) with the subject in a light-weight gown or underwear. WC was measured to the nearest $0.1 \mathrm{~cm}$ in a horizontal plane at the level of the midpoint between the iliac crest and the costal margin after a normal expiration. BMI was calculated as body weight $(\mathrm{kg})$ divided by height squared $\left(\mathrm{m}^{2}\right)$.

\section{Menopause status}

Menopause status was categorized into pre- and post-menopausal. Menopause was determined based on self-report. We asked whether the participant was menstruating currently and obtained the age of natural menopause if she had experienced menopause. Women were categorized as pre-menopausal if a participant answered 'yes' to the question: 'do you currently menstruate?' If a woman answered 'no', we considered her to be post-menopausal except if she was pregnant or breastfeeding.

\section{Blood pressure measurements and laboratory data}

Blood pressure was measured three times by trained nurses with a mercury sphygmomanometer (Baumanometer; Baum, Copiague, NY, USA) in a seated position after a 5-min rest. The final blood pressure value was obtained by averaging the values of the second and third blood pressure measurements.

Blood samples were obtained by venipuncture during the physical examination after a minimum 8-h overnight fast. Serum glucose, total cholesterol, high-density lipoprotein cholesterol, triglycerides and creatinine were measured enzymatically using a Hitachi automatic analyzer 7600 (Tokyo, Japan).

\section{Other variables}

Age (years), cigarette smoking history (current smoker, ex-smoker or nonsmoker) and physical activity level (walk, moderate or strenuous activity) were obtained using a self-administered questionnaire and were assessed by the interviewers. Total energy intake and the intake from carbohydrates, proteins and fats were assessed using a 24-h dietary recall. We categorized a participant as having hypertension if any of the following criteria were met: current use of antihypertensive medication (self-report), systolic blood pressure (SBP) of $140 \mathrm{~mm} \mathrm{Hg}$ or higher or diastolic blood pressure (DBP) of $90 \mathrm{~mm} \mathrm{Hg}$ or higher. We categorized a participant as having diabetes if any of the following criteria were met: current use of an oral hypoglycemic agent or insulin, or serum fasting glucose level of $126 \mathrm{mg} \mathrm{dl}^{-1}$ or higher. A participant was categorized as having hyperlipidemia if any of the following criteria were met: current use of lipid-lowering medication, serum total cholesterol level of $240 \mathrm{mg} \mathrm{dl}^{-1}$ or higher, or serum triglyceride level of $200 \mathrm{mg} \mathrm{dl}^{-1}$ or higher.

\section{Statistical analysis}

Statistical analyses were performed using SPSS (version 18.0; SPSS, Chicago, IL, USA). We incorporated sample weights, and adjusted the analyses for the complex sample design of the survey. Survey sample weights were used in all of the analyses to produce estimates that were representative of the noninstitutionalized civilian Korean population. All measured values are described as mean values with $95 \%$ CIs for continuous variables after analysis of variance, and as frequencies and percentages for categorical variables. To assess differences in characteristics, lifestyle and blood pressure between pre- and post-menopausal women, Student's $t$-test was used for means with $95 \% \mathrm{CI}$, and the $\chi^{2}$ test to analyze categorical variables. Categories of BMI were defined according to the standard World Health Organization classification. We used a multiple linear regression model to assess correlations between anthropometric measures and blood pressure. In the first step, correlation models were adjusted for age, menopausal status and lifestyle factors; in the second, we adjusted the BMI model for weight, WC or both, and the WC model for weight, BMI or both. In addition, we assessed correlations between WC and blood pressure across two categories of BMI: $<25 \mathrm{~kg} \mathrm{~m}^{-2}$ and $\geqslant 25 \mathrm{~kg} \mathrm{~m}^{-2}$. A two-tailed $P$-value of $<0.05$ was considered statistically significant.

\section{RESULTS}

Demographic characteristics and anthropometry of pre- and postmenopausal women

Table 1 summarizes the descriptive characteristics of the participants by menopausal status. Mean ages were 47.99 (95\% CI 47.82-48.17) and 52.54 (95\% CI 52.28-52.79) years for pre- and post-menopausal women, respectively $(P<0.001)$. The pre-menopausal women tended to be heavier and taller than the post-menopausal women, but there was no statistically significant difference in BMI between the two groups $\left(23.80 \mathrm{~kg} \mathrm{~m}^{-2}, 95 \%\right.$ CI $23.57-24.03$ vs. $23.90 \mathrm{~kg} \mathrm{~m}^{-2}, 95 \% \mathrm{CI}$ 23.53-24.27, $P=0.617)$. However, the WC of the post-menopausal women was significantly greater than that of the pre-menopausal women $(80.44 \mathrm{~cm}, 95 \%$ CI $79.36-81.52$ vs. $78.94 \mathrm{~cm}, 95 \%$ CI $78.27-$ 79.61, $P=0.013)$. Rates of hypertension and hyperlipidemia were significantly higher in the post-menopausal women (hypertension: $23.1 \%$ vs. $17.2 \%, P=0.031$; hypercholesterolemia: $21.8 \%$ vs. $8.4 \%$, $P<0.001$; hypertriglyceridemia: $17.1 \%$ vs. $8.2 \%, P=0.003)$, but there was no difference in the prevalence of diabetes mellitus $(8.4 \%$ vs. $6.3 \%, P=0.297)$. The post-menopausal group was more likely to take medications for hypertension and hyperlipidemia ( $15.7 \%$ vs. $10.1 \%$, $P=0.015$ and $5.1 \%$ vs. $2.0 \%, P=0.002$, respectively) but not for diabetes mellitus (3.7\% vs. 3.1\%, $P=0.685)$.

Comparison of lifestyles in the pre- and post-menopausal women As shown in Table 2, smoking habits and physical activity were not different in the two groups. Although the daily intake of carbohydrates was greater in the post-menopausal women $\left(306.67 \mathrm{~g} \mathrm{day}^{-1}\right.$, 95\% CI 291.13-322.21 vs. $284.38 \mathrm{~g} \mathrm{day}^{-1}$, 95\% CI 276.68-292.08, $P=0.011)$, total energy and sodium intake were not different ( $P=0.416$ and $P=0.429$, respectively).

\section{Comparison of blood pressure and laboratory data between the pre- and post-menopausal women}

Table 3 shows that SBP and DBP were significantly higher in the postmenopausal women than in the pre-menopausal women $(118.33 \mathrm{~mm}$ $\mathrm{Hg}$, 95\% CI 116.52-120.15 vs. $115.22 \mathrm{~mm} \mathrm{Hg}$, 95\% CI 114.17-116.28, 
Table 1 Descriptive characteristics of pre- and post-menopausal women aged 45-55 years participating in the KNHANES 2007-2010

\begin{tabular}{|c|c|c|c|}
\hline Characteristics & Pre-menopausal women $(\mathrm{n}=1029)$ & Post-menopausal women $(n=393)$ & P-value \\
\hline Age, years & $47.99(47.82-48.17)$ & $52.54(52.28-52.79)$ & $<0.001$ \\
\hline Height, cm & $157.31(156.94-157.69)$ & $155.28(154.65-155.91)$ & $<0.001$ \\
\hline Waist circumference, $\mathrm{cm}$ & $78.94(78.27-79.61)$ & $80.44(79.36-81.52)$ & 0.013 \\
\hline$B M I, \mathrm{kgm}^{-2}$ & $23.80(23.57-24.03)$ & $23.90(23.53-24.27)$ & 0.617 \\
\hline$<18.5$ & $21(2.3 \%)$ & $10(3.1 \%)$ & 0.714 \\
\hline \multicolumn{4}{|l|}{ Chronic disease, $\mathrm{n}(\%)$} \\
\hline Diabetes mellitus & $54(6.3 \%)$ & $29(8.4 \%)$ & 0.297 \\
\hline Hypertension & $189(17.2 \%)$ & $100(23.1 \%)$ & 0.031 \\
\hline \multicolumn{4}{|l|}{ Hyperlipidemia } \\
\hline Hypercholesterolemia & $97(8.4 \%)$ & $79(21.8 \%)$ & $<0.001$ \\
\hline Antihypertensive drug & $110(10.1 \%)$ & $65(15.7 \%)$ & 0.015 \\
\hline Lipid-lowering drug & $25(2.0 \%)$ & $20(5.1 \%)$ & 0.002 \\
\hline
\end{tabular}

Abbreviations: $\mathrm{BMI}$, body mass index; $\mathrm{Cl}$, confidence interval.

Continuous variables are presented as mean $(95 \% \mathrm{CI})$ and dichotomous variables presented as $n(\%)$, unless otherwise specified.

Table 2 Lifestyles of pre- and post-menopausal women aged 45-55 years participating in the KNHANES 2007-2010

\begin{tabular}{|c|c|c|c|}
\hline Cigarette smoking status, n (\%) & & & 0.085 \\
\hline Current smoker & $30(2.9 \%)$ & $17(4.9 \%)$ & \\
\hline Non-smoker & $979(95.2 \%)$ & $363(91.7 \%)$ & \\
\hline \multicolumn{4}{|l|}{ Physical activity } \\
\hline Strenuous, $n(\%)$ & $169(16.3 \%)$ & $50(13.9 \%)$ & 0.337 \\
\hline \multicolumn{4}{|l|}{ Diet } \\
\hline Total intake, kcal day ${ }^{-1}$ & $1650.93(1607.74-1694.13)$ & 1689.44 (1604.49-1774.39) & 0.416 \\
\hline Carbohydrate, g day ${ }^{-1}$ & $284.38(276.68-292.08)$ & $306.67(291.13-322.21)$ & 0.011 \\
\hline Protein, g day ${ }^{-1}$ & $61.03(58.93-63.13)$ & $57.54(53.80-61.27)$ & 0.100 \\
\hline
\end{tabular}

type of walk, moderate and strenuous activity ( $>30 \mathrm{~min}$ and more than five times a week).

$P=0.003$ and $76.94 \mathrm{~mm} \mathrm{Hg}, 95 \%$ CI $75.88-77.99$ vs. $75.25 \mathrm{~mm} \mathrm{Hg}$, 95\% CI 74.57-75.93, $P=0.009$, respectively). Pulse pressure was higher in the post-menopausal women $(41.40 \mathrm{~mm} \mathrm{Hg}, 95 \%$ CI $40.33-$ 42.46 vs. $39.97 \mathrm{~mm} \mathrm{Hg}, 95 \%$ CI 39.29-40.66, $P=0.021$ ), but heart rate was not significantly different. Higher serum total cholesterol $(P<0.001)$ and triglycerides $(P=0.001)$ were noted in the postmenopausal women, but serum creatinine, fasting glucose and highdensity lipoprotein cholesterol were similar $(P=0.079,0.370$ and 0.785 , respectively).
Correlation between two anthropometric measures of obesity and blood pressure

There was a significant relationship between WC and BMI $\left(R^{2}=0.731, \beta=0.307,95 \%\right.$ CI $\left.0.293-0.322, P<0.001\right)$. A stratified analysis revealed that the relationship between WC and BMI in lean women (BMI $<25 \mathrm{~kg} \mathrm{~m}^{-2}$ ) and overweight women $\left(\mathrm{BMI} \geqslant 25 \mathrm{~kg} \mathrm{~m}^{-2}\right)$ was also significant $\left(R^{2}=0.481, \beta=0.209,95 \%\right.$ CI $0.191-0.228, P<0.001 ; R^{2}=0.513, \beta=0.226,95 \%$ CI $0.186-0.266$, $P<0.001$, respectively). 
Table 3 Blood pressure and laboratory data among pre- and post-menopausal women aged 45-55 years participating in the third KNHANES 2007-2010

\begin{tabular}{|c|c|c|c|}
\hline Variables & Pre-menopausal women $(\mathrm{n}=1029)$ & Post-menopausal women $(n=393)$ & P-value \\
\hline \multicolumn{4}{|l|}{ Blood pressure, $\mathrm{mm} \mathrm{Hg}$} \\
\hline Systolic & 115.22 (114.17-116.28) & 118.33 (116.52-120.15) & 0.003 \\
\hline Diastolic & $75.25(74.57-75.93)$ & $76.94(75.88-77.99)$ & 0.009 \\
\hline Pulse pressure, mm Hg & 39.97 (39.29-40.66) & $41.40(40.33-42.46)$ & 0.021 \\
\hline Heart rate, beats $\min ^{-1}$ & $69.17(68.50-69.84)$ & $69.02(67.89-70.14)$ & 0.813 \\
\hline Creatinine, $\mathrm{mg} \mathrm{dl}^{-1}$ & $0.73(0.72-0.74)$ & $0.76(0.73-0.79)$ & 0.079 \\
\hline Fasting glucose, $\mathrm{mg} \mathrm{dl}^{-1}$ & $96.28(94.85-97.71)$ & 97.45 (95.27-99.63) & 0.370 \\
\hline \multicolumn{4}{|l|}{ Cholesterol, mgdl-1 } \\
\hline $\mathrm{TC}$ & 189.39 (187.31-191.46) & 210.06 (205.62-214.51) & $<0.001$ \\
\hline TG & 111.91 (106.06-117.75) & 137.20 (124.06-150.35) & 0.001 \\
\hline HDL-C & $50.76(50.01-51.51)$ & $50.55(49.22-51.88)$ & 0.785 \\
\hline
\end{tabular}

Abbreviations: $\mathrm{Cl}$, confidence interval; HDL-C, high-density lipoprotein cholesterol; TC, total cholesterol, TG, triglyceride.

Continuous variables are presented as mean $(95 \% \mathrm{Cl})$, unless otherwise specified.

Table 4 Relationship between anthropometric measure and blood pressure

\begin{tabular}{|c|c|c|c|c|}
\hline & Regression coefficient $(95 \% \mathrm{Cl}$ ) & P-value & Regression coefficient (95\% CI) & P-value \\
\hline No adjustment & 1.417 (1.149 to 1.685$)$ & $<0.001$ & 0.794 (0.630 to 0.958$)$ & $<0.001$ \\
\hline Basic adjustment ${ }^{\mathrm{a}}$ & 1.339 (1.073 to 1.604$)$ & $<0.001$ & 0.761 (0.600 to 0.923$)$ & $<0.001$ \\
\hline Basic adjustment + weight & $1.185(0.590$ to 1.781$)$ & $<0.001$ & $0.393(0.027$ to 0.760$)$ & 0.035 \\
\hline \multicolumn{5}{|l|}{ Waist circumference } \\
\hline No adjustment & 0.503 (0.399 to 0.607$)$ & $<0.001$ & $0.254(0.193$ to 0.315$)$ & $<0.001$ \\
\hline Basic adjustment ${ }^{\mathrm{a}}$ & $0.480(0.375$ to 0.585$)$ & $<0.001$ & $0.245(0.184$ to 0.306$)$ & $<0.001$ \\
\hline Basic adjustment + weight & $0.364(0.162$ to 0.566$)$ & $<0.001$ & $0.058(-0.053$ to 0.169$)$ & 0.305 \\
\hline Basic adjustment $+\mathrm{BMI}$ & $0.248(0.035$ to 0.460$)$ & 0.022 & $0.035(-0.092$ to 0.163$)$ & 0.588 \\
\hline
\end{tabular}

Abbreviations: BMI, body mass index; $\mathrm{Cl}$, confidence interval.

${ }^{a}$ Adjusted for age, menopausal status, cigarette smoking status, physical activity level and amount of carbohydrate and sodium.

Table 4 shows the correlation between BMI or WC and blood pressure with or without additional adjustment for other anthropometric variables. In the BMI model, the correlation coefficients for SBP decreased after adjustment for body weight or WC but were still significant ( $\beta=0.771,95 \%$ CI $0.101-1.441, P=0.024$ ). However, the relationship between DBP and BMI was not significant after additional adjustment for weight and WC ( $\beta=0.407,95 \% \mathrm{CI}-0.024$ to $0.838, P=0.064)$. In the WC model, although the relationship with SBP was weak after additional adjustment, it remained significant after accounting for weight and BMI ( $\beta=0.250,95 \%$ CI $0.024-0.476$, $P=0.030)$. However, the relationship with DBP was not significant after adjusting for weight $(\beta=0.058,95 \%$ CI -0.053 to 0.169 , $P=0.305)$.

Correlation between fat distribution and blood pressure in lean and overweight or obese women

A stratified analysis revealed that in lean women $\left(\mathrm{BMI}<25 \mathrm{~kg} \mathrm{~m}^{-2}\right)$, WC was significantly and positively correlated with SBP $(\beta=0.358$,
95\% CI 0.138 to $0.579, P=0.001)$ but not with DBP $(\beta=0.049,95 \%$ CI -0.084 to $0.181, P=0.470$; Table 5 ). In overweight women (BMI $\geqslant 25 \mathrm{~kg} \mathrm{~m}^{-2}$ ), WC was not correlated with SBP and DBP.

\section{DISCUSSION}

In this cross-sectional study of 1422 middle-aged women, WC was significantly associated with SBP before and after adjusting for age and BMI. In the stratified analysis, these associations were significant in non-obese women (BMI $<25 \mathrm{~kg} \mathrm{~m}^{-2}$ ) but not in obese women $\left(\mathrm{BMI} \geqslant 25 \mathrm{~kg} \mathrm{~m}^{-2}\right)$.

The increase in blood pressure after menopause is a complex, multifaceted problem, and the specific mechanism responsible for post-menopausal hypertension has not been elucidated. ${ }^{32}$ Age, menopause and obesity are known to have major roles in the blood pressure increase. ${ }^{10-13}$ However, they are related to each other. ${ }^{28}$ Age is a confounding factor when studying the influence of menopause on blood pressure because menopause coincides with aging. There has been a long standing debate over the link between age and the 
Table 5 Relationship between waist circumference and blood pressure stratified by BMI category

\begin{tabular}{|c|c|c|c|c|}
\hline & \multicolumn{2}{|c|}{ Systolic blood pressure } & \multicolumn{2}{|c|}{ Diastolic blood pressure } \\
\hline & Regression coefficient $(95 \% \mathrm{Cl})$ & P-value & Regression coefficient $(95 \% \mathrm{Cl}$ ) & P-value \\
\hline \multicolumn{5}{|l|}{ Waist circumference } \\
\hline $\mathrm{BMI}<25 \mathrm{~kg} \mathrm{~m}^{-2}(n=972)$ & $0.358(0.138$ to 0.579$)$ & 0.001 & $0.049(-0.084$ to 0.181$)$ & 0.470 \\
\hline $\mathrm{BMI} \geqslant 25 \mathrm{~kg} \mathrm{~m}^{-2}(n=447)$ & $0.158(-0.212$ to 0.528$)$ & 0.402 & $-0.031(-0.226$ to 0.163$)$ & 0.753 \\
\hline
\end{tabular}

Abbreviations: $\mathrm{BMI}$, body mass index; $\mathrm{Cl}$, confidence interval.

Adjusted for age, menopausal status, weight, cigarette smoking status, physical activity level, and amount of carbohydrate and sodium.

post-menopausal increase in blood pressure. ${ }^{10,12}$ Therefore, we analyzed women in a narrow age range (from 45 to 55) to minimize the influence of age and concentrated on the relationship of obesity with blood pressure after adjusting for both age and menopausal status.

Obesity is known to be closely related with blood pressure and hypertension. Among measures of obesity, body weight, BMI and WC are frequently used in clinical practice or research. Although BMI is often used at the population level, it has limitations for discrimination at the individual level, and numerous types of metabolic abnormality, including hypertension, have been noted in individuals with similar BMIs. ${ }^{20}$ In this study, both lower height and weight in post-menopausal women resulted in no difference in BMI. Body weight generally increases after menopause, and yet this study showed the opposite result. The weight loss first seems to be related to the decrease in height. When adjusting for the difference in the height of women before and after menopause, the finding was not significant (58.33 vs. $58.62 \mathrm{~kg}, P=0.568$ ). Second, in this study, a high, but not significant, proportion of post-menopausal women were smokers $(P=0.085)$. Also, the effect of smoking on the paradox of high waist-to-hip ratio and low BMI was previously reported in the Korean population. ${ }^{33}$ This suggests that further study needs to be done to determine whether smoking induces the decrease in the height. WC has been suggested to be a simple, inexpensive, easy and effective indicator of body fat distribution, ${ }^{34}$ and is well correlated with the results of abdominal imaging. ${ }^{35}$ We found that the WCs of the pre- and post-menopausal groups were significantly different, but that their BMIs were not. WC was also correlated with blood pressure like BMI was. This finding suggests that body shape is changed by the altered body fat distribution, which may be as important an influence on the blood pressure increase as the increase in total body fat. However, WC alone may be an inadequate read-out for body fat distribution because previous studies have failed to verify a significant effect of menopause on body fat distribution after adjusting for age, with WC as a surrogate for central obesity. ${ }^{36-38}$ This failure may be related to variability in measurement location ${ }^{39}$ or to WC itself being an insufficient indicator of central obesity.

In this study, there was no significant relationship between WC and blood pressure in overweight and obese women (BMI $\geqslant 25 \mathrm{~kg} \mathrm{~m}^{-2}$ ). It can be suggested that abdominal fat may no longer have an additional effect on blood pressure, which may be due to an already high amount of total body fat. This finding is similar to the relationship between $\mathrm{WC}$ and sex hormones in a previous study, which showed that WC was associated with levels of sex hormones and sex hormone-binding globulins in non-obese women but not in obese women. ${ }^{40}$ Estrogen levels and sex hormone-binding globulins are known to decline and free testosterone levels are known to increase after menopause, and this is thought to induce central obesity. ${ }^{41}$ Dramatic alterations in the dynamics of estrogen production have been suggested to be responsible for changes in body fat distribution. ${ }^{42}$

In addition to sex hormones, body fat distribution could be related to the effect of aging ${ }^{43,44}$ or physiological and/or behavioral changes. ${ }^{45,46}$ However, studies using computed tomography, a highly reliable method for measuring body fat distribution, found an effect of the menopausal transition on body fat distribution that was significant after adjusting for BMI and age. ${ }^{47}$ The changes in body composition and fat distribution occurred even in non-obese menopausal women. ${ }^{48}$ In a study by Kotani et al., ${ }^{49}$ a steeper regression line for the association between abdominal obesity and age was found in post-menopausal women, suggesting that menopause accelerates the selective deposition of intraabdominal fat.

The mechanisms linking central obesity to blood pressure are not clearly understood. The deposition of adipose tissue in the visceral area has been associated with insulin resistance, which contributes to the development of hyperinsulinemia. This may lead to increased sympathetic nervous system stimulation, enhanced sodium resorption and stimulation of the renin-angiotensin-aldosterone system, which could elevate blood pressure. ${ }^{50,51}$ Therefore, an effect of the accelerated change in body fat distribution on blood pressure at menopause may be another cause of the increased blood pressure and high prevalence of hypertension in post-menopausal women.

Several limitations of this study are worth noting. The study was cross-sectional and there may been a selection bias because we excluded women for whom did not have complete data. As the KNHNES does not fully cover menstrual cycle frequency and regularity, we could not divide subjects into pre-, peri- and postmenopausal categories. Although we excluded women who had recently entered menopause, some peri-menopausal women may have been included in the two groups. It is known that the agreement between self-reported menopausal status and gynecologists' medical records is relatively high, ${ }^{52}$ but the reliability of self-reported menstruation status may be a limitation of this study. Finally, it may not be possible to generalize these findings to all Korean women. Nevertheless, the strength of this study lies in having clinically measured anthropometry outcomes and blood pressure measurements in a large nationally representative sample.

In summary, we analyzed women ranging from 45 to 55 years of age from the 2007 to 2010 KNHANES, a large population-based survey. Our findings suggest that the changes in body fat distribution through the transition into menopause are associated with SBP independent of total body fat in middle-aged women. Therefore, it can be suggested that the change in body fat composition may be another cause of menopause-related changes in blood pressure. 
1 Ong KL, Tso AW, Lam KS, Cheung BM. Gender difference in blood pressure control and cardiovascular risk factors in Americans with diagnosed hypertension. Hypertension 2008; 51: 1142-1148.

2 Ong KL, Cheung BM, Man YB, Lau CP, Lam KS. Prevalence, awareness, treatment, and control of hypertension among United States adults 1999-2004. Hypertension 2007; 49: 69-75.

3 Yanes LL, Reckelhoff JF. Postmenopausal hypertension. Am J Hypertens 2011; 24: 740-749.

4 Martins D, Nelson K, Pan D, Tareen N, Norris K. The effect of gender on age-related blood pressure changes and the prevalence of isolated systolic hypertension among older adults: data from NHANES III. J Gend Specif Med 2001; 4(10-13): 20.

5 Taddei S. Blood pressure through aging and menopause. Climacteric 2009; 12(Suppl 1): $36-40$.

6 Skafar DF, Xu R, Morales J, Ram J, Sowers JR. Clinical review 91: female sex hormones and cardiovascular disease in women. J Clin Endocrinol Metab 1997; 82: 3913-3918.

7 Barrett-Connor E, Bush TL. Estrogen and coronary heart disease in women. JAMA 1991; 265: 1861-1867.

8 Barton M, Meyer MR. Postmenopausal hypertension: mechanisms and therapy. Hypertension 2009; 54: 11-18.

9 Reckelhoff JF, Fortepiani LA. Novel mechanisms responsible for postmenopausal hypertension. Hypertension 2004; 43: 918-923.

10 Coylewright M, Reckelhoff JF, Ouyang P. Menopause and hypertension: an age-old debate. Hypertension 2008; 51: 952-959.

11 Izumi $Y$, Matsumoto K, Ozawa Y, Kasamaki Y, Shinndo A, Ohta M, Jumabay M, Nakayama T, Yokoyama E, Shimabukuro H, Kawamura H, Cheng Z, Ma Y, Mahmut M. Effect of age at menopause on blood pressure in postmenopausal women. $\mathrm{Am} J$ Hypertens 2007; 20: 1045-1050.

12 Casiglia E, Tikhonoff V, Caffi S, Bascelli A, Schiavon L, Guidotti F, Saugo M, Giacomazzo M, Martini B, Mazza A, D'Este D, Pessina AC. Menopause does not affect blood pressure and risk profile, and menopausal women do not become similar to men. J Hypertens 2008; 26: 1983-1992.

13 Rappelli A. Hypertension and obesity after the menopause. J Hypertens Suppl 2002; 20: S26-S28.

14 PoehIman ET, Toth MJ, Gardner AW. Changes in energy balance and body composition at menopause: a controlled longitudinal study. Ann Intern Med 1995; 123: 673-675.

15 Berchtold P, Jorgens V, Finke C, Berger M. Epidemiology of obesity and hypertension. Int J Obes 1981; 5(suppl 1): 1-7.

16 MacMahon S, Cutler J, Brittain E, Higgins M. Obesity and hypertension: epidemiological and clinical issues. Eur Heart J 1987; 8(Suppl B): 57-70.

17 Kastarinen MJ, Nissinen AM, Vartiainen EA, Jousilahti PJ, Korhonen HJ, Puska PM. Tuomilehto Blood pressure levels and obesity trends in hypertensive and normotensive Finnish population from 1982 to 1997. J Hypertens 2000; 18: 255-262.

18 Stamler R, Stamler J, Riedlinger WF, Algera G, Roberts RH. Weight and blood pressure. Findings in hypertension screening of 1 million Americans. JAMA 1978; 240 1607-1610.

19 Seidell JC, Perusse L, Despres JP, Bouchard C. Waist and hip circumferences have independent and opposite effects on cardiovascular disease risk factors: the Quebec Family Study. Am J Clin Nutr 2001; 74: 315-321.

20 Fox CS, Massaro JM, Hoffmann U, Pou KM, Maurovich-Horvat P, Liu CY, Vasan RS, Murabito JM, Meigs JB, Cupples LA, D'Agostino Sr. RB, O'Donnell CJ. Abdominal visceral and subcutaneous adipose tissue compartments: association with metabolic risk factors in the Framingham Heart Study. Circulation 2007; 116: 39-48.

21 Lovejoy JC, Champagne CM, de Jonge L, Xie H, Smith SR. Increased visceral fat and decreased energy expenditure during the menopausal transition. Int J Obes (Lond) 2008; 32: 949-958.

22 Guthrie JR, Dennerstein L, Taffe JR, Lehert P, Burger HG. The menopausal transition: a 9-year prospective population-based study. The Melbourne Women's Midlife Health Project. Climacteric 2004; 7: 375-389.

23 Guthrie JR, Dennerstein L, Dudley EC. Weight gain and the menopause: a 5-year prospective study. Climacteric 1999; 2: 205-211.

24 Gambacciani M, Ciaponi M, Cappagli B, Benussi C, De Simone L, Genazzani AR. Climacteric modifications in body weight and fat tissue distribution. Climacteric 1999; 2: $37-44$.

25 Svendsen OL, Hassager C, Christiansen C. Age- and menopause-associated variations in body composition and fat distribution in healthy women as measured by dual-energy X-ray absorptiometry. Metabolism 1995; 44: 369-373.

26 Ozbey N, Sencer E, Molvalilar S, Orhan Y. Body fat distribution and cardiovascular disease risk factors in pre- and postmenopausal obese women with similar BMI. Endocr J 2002; 49: 503-509.

27 Azizi F, Esmaillzadeh A, Mirmiran P, Ainy E. Is there an independent association between waist-to-hip ratio and cardiovascular risk factors in overweight and obese women? Int J Cardiol 2005; 101: 39-46.

28 Chang CJ, Wu CH, Yao WJ, Yang YC, Wu JS, Lu FH. Relationships of age, menopause and central obesity on cardiovascular disease risk factors in Chinese women. Int J Obes Relat Metab Disord 2000; 24: 1699-1704.
29 Poehlman ET, Toth MJ, Ades PA, Rosen CJ. Menopause-associated changes in plasma lipids, insulin-like growth factor I and blood pressure: a longitudinal study. Eur J Clin Invest 1997; 27: 322-326.

$30 \mathrm{Kim}$ Y, Lee BK. Iron deficiency increases blood manganese level in the Korean general population according to KNHANES 2008. Neurotoxicology 2011; 32: 247-254.

$31 \mathrm{Kim}$ Y, Lee BK. Association between urinary arsenic and diabetes mellitus in the Korean general population according to KNHANES 2008. Sci Total Environ Res 2011; 409: 4054-4062.

32 Lobo RA. What is the effect of estrogen on blood pressure after menopause? Menopause 2006; 13: 331-333.

33 Jee SH, Lee SY, Nam CM, Kim SY, Kim MT. Effect of smoking on the paradox of high waist-to-hip ratio and low body mass index. Obes Res 2002; 10: 891-895.

34 Cornier MA, Despres JP, Davis N, Grossniklaus DA, Klein S, Lamarche B, LopezJimenez F, Rao G, St-Onge MP, Towfighi A, Poirier P. Assessing Adiposity: a scientific statement from the American Heart Association. Circulation 2011; 124: 1996-2019.

35 Pouliot MC, Despres JP, Lemieux S, Moorjani S, Bouchard C, Tremblay A, Nadeau A, Lupien PJ. Waist circumference and abdominal sagittal diameter: best simple anthropometric indexes of abdominal visceral adipose tissue accumulation and related cardiovascular risk in men and women. Am J Cardiol 1994; 73: 460-468.

36 Pasquali R, Casimirri F, Labate AM, Tortelli O, Pascal G, Anconetani B, Gatto MR, Flamia R, Capelli M, Barbara L. Body weight, fat distribution and the menopausal status in women. The VMH Collaborative Group. Int J Obes Relat Metab Disord 1994; 18: 614-621.

37 Troisi RJ, Wolf AM, Mason JE, Klingler KM, Colditz GA. Relation of body fat distribution to reproductive factors in pre- and postmenopausal women. Obes Res 1995; 3: 143-151.

38 Zamboni M, Armellini F, Milani MP, De Marchi M, Todesco T, Robbi R, BergamoAndreis IA, Bosello O. Body fat distribution in pre- and post-menopausal women: metabolic and anthropometric variables and their inter-relationships. Int J Obes Relat Metab Disord 1992; 16: 495-504.

39 Ross R, Berentzen T, Bradshaw AJ, Janssen I, Kahn HS, Katzmarzyk PT, Kuk JL, Seidell JC, Snijder MB, Sorensen TI, Despres JP. Does the relationship between waist circumference, morbidity and mortality depend on measurement protocol for waist circumference? Obes Rev 2008; 9: 312-325

40 Liedtke S, Schmidt ME, Vrieling A, Lukanova A, Becker S, Kaaks R, Zaineddin AK, Buck K, Benner A, Chang-Claude J, Steindorf K. Postmenopausal sex hormones in relation to body fat distribution. Obesity (Silver Spring) 2012; 20: 1088-1095.

41 Kaye SA, Folsom AR, Soler JT, Prineas RJ, Potter JD. Associations of body mass and fat distribution with sex hormone concentrations in postmenopausal women. Int $J$ Epidemiol 1991; 20: 151-156.

42 Svendsen OL, Hassager C, Christiansen C. Relationships and independence of body composition, sex hormones, fat distribution and other cardiovascular risk factors in overweight postmenopausal women. Int J Obes Relat Metab Disord 1993; 17: 459-463.

43 Matthews KA, Abrams B, Crawford S, Miles T, Neer R, Powell LH, Wesley D. Body mass index in mid-life women: relative influence of menopause, hormone use, and ethnicity. Int J Obes Relat Metab Disord 2001; 25: 863-873.

44 Sternfeld B, Wang H, Quesenberry Jr CP, Abrams B, Everson-Rose SA, Greendale GA, Matthews KA, Torrens JI, Sowers M. Physical activity and changes in weight and waist circumference in midlife women: findings from the Study of Women's Health Across the Nation. Am J Epidemiol 2004; 160: 912-922.

45 Heymsfield SB, Gallagher D, Poehlman ET, Wolper C, Nonas K, Nelson D, Wang ZM. Menopausal changes in body composition and energy expenditure. Exp Gerontol 1994; 29: 377-389.

46 Van Pelt RE, Jones PP, Davy KP, Desouza CA, Tanaka H, Davy BM, Seals DR. Regular exercise and the age-related decline in resting metabolic rate in women. J Clin Endocrinol Metab 1997; 82: 3208-3212.

47 Tchernof A, Poehlman ET, Despres JP. Body fat distribution, the menopause transition, and hormone replacement therapy. Diabetes Metab 2000; 26: 12-20.

48 Abdulnour J, Doucet E, Brochu M, Lavoie JM, Strychar I, Rabasa-Lhoret R, Prud'homme D. The effect of the menopausal transition on body composition and cardiometabolic risk factors: a Montreal-Ottawa New Emerging Team group study. Menopause 2012; 19: 760-767.

49 Kotani K, Tokunaga K, Fujioka S, Kobatake T, Keno Y, Yoshida S, Shimomura I, Tarui S, Matsuzawa Y. Sexual dimorphism of age-related changes in whole-body fat distribution in the obese. Int J Obes Relat Metab Disord 1994; 18: 207-212.

50 Landsberg L. Diet, obesity and hypertension: an hypothesis involving insulin, the sympathetic nervous system, and adaptive thermogenesis. Q J Med 1986; 61: 1081-1090.

51 Sims EA. Mechanisms of hypertension in the syndromes of obesity. Int J Obes 1981; 5(suppl 1): 9-18.

52 Clavel-Chapelon F, Dormoy-Mortier N. A validation study on status and age of natural menopause reported in the $\mathrm{E} 3 \mathrm{~N}$ cohort. Maturitas 1998; 29. 99-103. 